\title{
Análise da vulnerabilidade natural das águas subterrâneas por geoprocessamento no campus da UFSM - RS
}

\section{The analysis of the natural vulnerability of groundwater by geoprocessing on the campus of the Federal University of Santa Maria - RS}

\author{
Fabiano André Marion \\ Universidade do Oeste do Paraná - Francisco Beltrão \\ José Américo de Mello Filho \\ José Luiz Silvério da Silva \\ Universidade Federal de Santa Maria
}

\begin{abstract}
Resumo: A pesquisa teve como objetivo realizar uma avaliação da vulnerabilidade natural à contaminação das águas subterrâneas no campus da Universidade Federal de Santa Maria - RS (UFSM). A metodologia baseia-se na análise ambiental por geoprocessamento, conforme Xavier da Silva (2001). Do total da área em estudo, 47,17\% dela foi identificada como de média vulnerabilidade, $32,12 \%$ como de baixa vulnerabilidade e $20,71 \%$ como de alta vulnerabilidade. Essa última é a que exige um maior cuidado com respeito a sua ocupação, pois além de ser a área mais suscetível à contaminação dos aquíferos, nela se situa o setor urbanizado do campus.
\end{abstract}

Palavras-chave: Sistema Aquífero Guarani. Recursos hídricos subterrâneos. Plano Diretor. Vulnerabilidade natural.

\begin{abstract}
The research is intended to assess the vulnerability of groundwater to contamination at the Campus of the Federal University of Santa Maria (UFSM). Its methodology is based on an environmental analysis by the use of geoprocessing, following Xavier da Silva (2001). $47.17 \%$ of the total study area has been identified as of moderate vulnerability, $32.12 \%$ of low vulnerability and $20.71 \%$ of high vulnerability. Especially, the last one requires greater attention in respect to its occupation as, beyond the area being most susceptible to contamination of aquifers, it is also located in the urbanized sector of the campus.
\end{abstract}

Keywords: Guarani Aquifer System. Groundwater hydrological ressources. Master plan. Natural vulnerability. 


\section{INTRODUÇÃO}

Atualmente, tem-se uma grande procura pela água subterrânea, cada vez mais utilizada como fonte para o abastecimento, tanto urbano quanto rural, visto que as águas superficiais tornam-se cada vez mais poluídas e escassas. Prova disso é a crescente demanda pela perfuração de poços que, quando mal realizada ou abandonada, torna-se ponto potencial de poluição. Estima-se que em 2005 existissem, aproximadamente, 400.000 poços distribuídos por todo o país. (ZOBY; OLIVEIRA, 2005).

Em se tratando de recursos hídricos subterrâneos, a prevenção à poluição e o planejamento dos usos dão-se por meio de estudos de proteção dos aquíferos, pelo controle das atividades humanas e pela identificação de áreas vulneráveis à contaminação, a fim de efetuar um planejamento ordenado em relação aos usos e ocupações do solo. Esses elementos, frente à sua grande importância no planejamento territorial, conforme o Código Estadual do Meio Ambiente, Lei Estadual $n^{\circ} 11.520 / 2000$, deverão ser indicados na elaboração de Planos Diretores e demais instrumentos de planejamento urbano.

O campus da Universidade Federal de Santa Maria (UFSM), por seguir essa tendência de uso, já perfurou, até o final do ano de 2008, aproximadamente 50 poços. Desses, 24 poços estão em atividade e capturam água do Sistema Aquífero Guarani que, em algumas épocas do ano, não supre a demanda requerida para atender às mais diversas finalidades desenvolvidas no campus. O Hospital Universitário (HUSM), por ser público e referência em casos de alta complexidade, atende a 45 municípios da região Centro-Oeste do estado do Rio Grande do Sul e, por isso, necessita de água em quantidade e qualidade, conforme Portaria do Ministério da Saúde $n^{0}$ 518/2004. (BRASIL, 2004). Com uma futura transferência para o campus dos cursos ainda hoje instalados no Centro de Santa Maria e com a abertura de novos cursos, a tendência é de aumento significativo desse consumo.

Nas pesquisas sobre recursos naturais, a sua representação cartográfica é de fundamental importância para a sua análise e compreensão, o que é aplicável também à hidrogeologia em geral e aos estudos de vulnerabilidade de aquíferos em particular. Nesse caso, é de extrema importância a identificação da fragilidade do terreno em percolar possíveis contaminantes, o que se denomina como mapeamento de vulnerabilidade. Esse procedimento possibilita dar subsídios ao planejamento adequado em relação aos usos e ocupações do solo, justificados, sobretudo, na legislação ambiental vigente.

Como a UFSM está elaborando seu Plano Diretor - e o seu abastecimento d'água é dependente, em grande parcela, das águas subterrâneas - urge um zoneamento ambiental de proteção dos aquíferos que avalie o potencial de poluição e as áreas vulneráveis à contaminação. Tal instrumento oferece fundamentos ao planejamento e implantação do Plano Diretor do campus de forma legal e ambientalmente responsável. Assim, o objetivo deste trabalho é, com o uso de técnicas de geoprocessamento, identificar áreas vulneráveis à contaminação das águas subterrâneas no campus da UFSM, a fim de subsidiar o seu adequado uso e ocupação.

Por geoprocessamento, entende-se como levantamento e a análise de situações ambientais representadas por conjuntos de variáveis georreferenciadas e integradas em uma base de dados digital. Faz-se necessário, por definição, contar com uma base cartográfica confiável sobre a qual coligirá seus dados, o que demanda conhecimentos sobre cartografia automatizada. Os objetivos do geoprocessamento, entretanto, centram-se na análise dos dados 
e não devem ser confundidos com os da cartografia automatizada. (XAVIER DA SILVA, 2001).

\section{CARACTERIZAÇÃO DA ÁREA EM ESTUDO}

O campus da UFSM abrange a Cidade Universitária Prof. José Mariano da Rocha Filho, situada no Bairro Camobi, município de Santa Maria, estado do Rio Grande do
Sul - RS, no qual é realizada a maior parte de suas atividades acadêmicas e administrativas. Localizado entre as coordenadas geodésicas $53^{\circ} 46^{\prime}$ a $53^{\circ} 43^{\prime}$ a Oeste de Greenwich e entre $29^{\circ} 42^{\prime} 30^{\prime \prime}$ a $29^{\circ} 45^{\prime}$ ao Sul do Equador, situa-se a $9 \mathrm{~km}$ do centro de Santa Maria e a $290 \mathrm{~km}$ de Porto Alegre (Figura 1). Estima-se, por dados da Prefeitura da Cidade Universitária, que no ano de 2008 circularam diariamente pelo campus cerca de 20.000 pessoas.

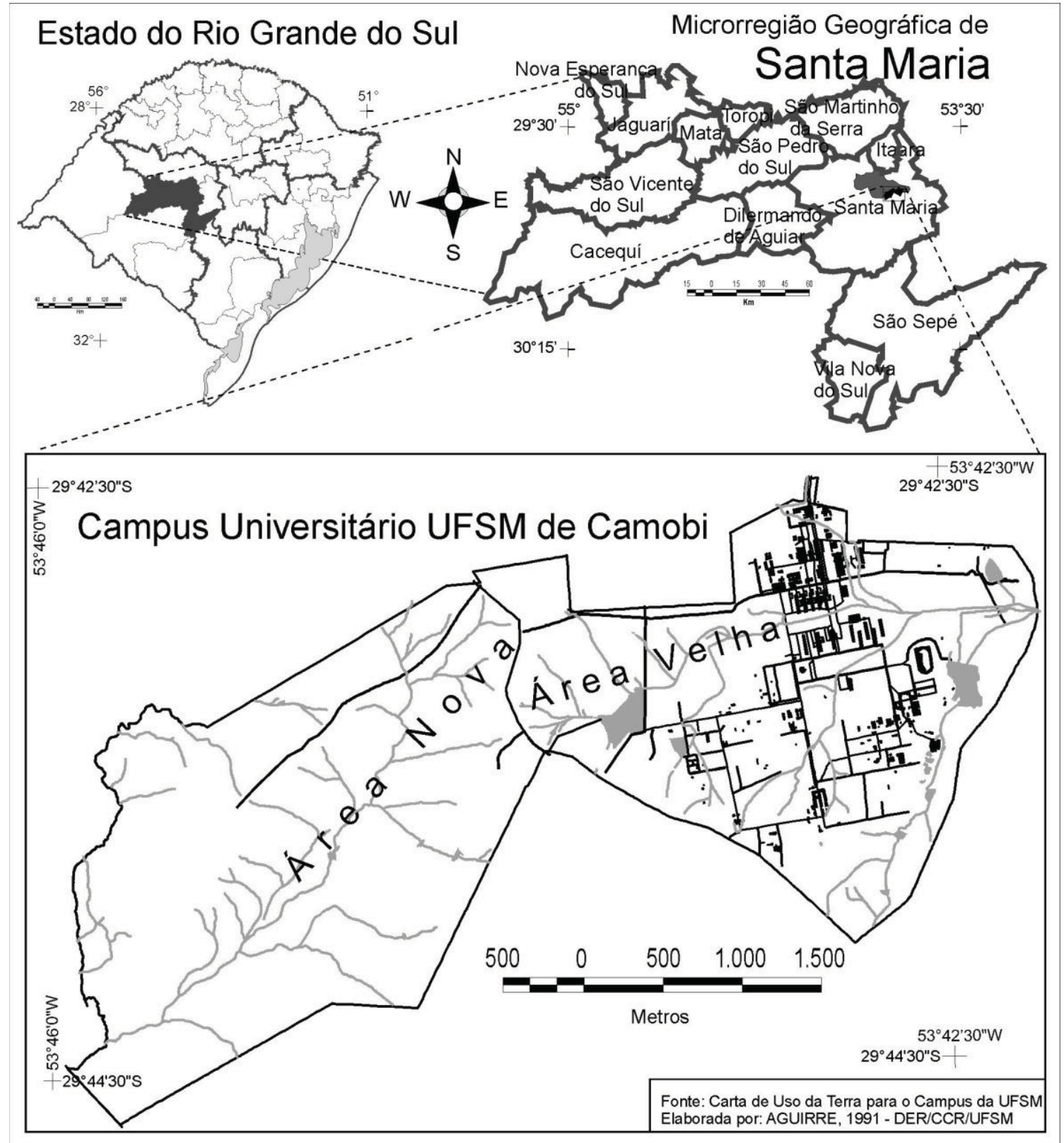

Figura 1 - Mapa de localização da área de estudo 
Sua área inicial era de 528,6649 hectares, conhecida como área velha, integrada hoje ao perímetro urbano de Santa Maria. Em 29 de abril de 1988, a Universidade adquiriu uma área de 600,7949 hectares, conhecida como área nova, e que está atualmente inserida na zona rural do município, o que totaliza 1.129,4598 hectares. (UFSM, 2008).

Para Nimmer (1990), o regime climático da área onde se enquadra o município de Santa Maria é caracterizado por precipitações regulares com índices pluviométricos anuais entre $1.500 \mathrm{~mm}$ a $1.750 \mathrm{~mm}$, com chuvas ocasionadas pela passagem de frentes frias, intensificadas pelo efeito orográfico do Rebordo do Planalto e, eventualmente, pela formação de frentes quentes. Esses índices são importantes na estimativa da recarga direta pela infiltração das águas meteóricas no subsolo. De acordo com Gregorashuk (2001), a maioria dos pesquisadores concorda com uma infiltração para os aquíferos de $1 \%$ a $3 \%$ da precipitação média anual. Já Hausman (1995) estimou para a área uma taxa de infiltração entre 3\% e $6 \%$ da precipitação média anual.

As litologias são representadas por rochas sedimentares da Bacia Sedimentar do Paraná, compostas por argilitos, siltitos e arenitos de diferentes unidades geológicas e granulações. Essas características, juntamente com as características morfológicas e climáticas, formam as chamadas Províncias Hidrogeológicas e Subprovíncias. De acordo com Hausman (1995), a área em estudo enquadra-se na Província Gondwânica, na qual, litologicamente, há o domínio de formações argilosas e arenosas que desaparecem por baixo da cobertura basáltica, situada ao Norte e a Oeste do Escudo Sulrriograndense e na Subprovíncia Rosário do Sul, assim caracterizada:

[...] é um aquífero hidroestrutural, onde pode ser observado um grupo de horizontes condutores, intercalados por aquicludes e aquitardos, formando um pacote cuja diversificação não é somente quanto à permeabilidade, como também quanto à qualidade da água. O horizonte estratigráfico que constitui esta Sub-Província é isolado dos outros por um topo e base impermeáveis, mergulhando estruturalmente na direção do pacote sedimentar Gondwânico a que pertencem, apresentando problemas locais quanto à circulação de água devido às características deposicionais. (HAUSMAN, 1995).

A divisão das formações geológicas mais utilizada para a região central do estado do Rio Grande do Sul é a proposta por Andreis et al. (1980 apud DA-ROSA, 2004). Ela sugere que os pacotes de litologias, dominantemente pelíticas aflorantes na área, fossem incluídos na formação Santa Maria, limitados na base pelos arenitos finos da formação Rio do Rastro, e, no topo, pelos arenitos de origem eólica da formação Botucatu. Essa seção sedimentar recebe o nome de Grupo Rosário do Sul, dividida nas formações Sanga do Cabral, Santa Maria e Caturrita. A zona urbana de Santa Maria possui as seções tipo das Formações Caturrita e Santa Maria. Essa última compõe a parte superficial predominante da litologia do campus da UFSM.

A formação Santa Maria é subdividida em dois membros: um inferior, denominado Membro Passo das Tropas, e um superior, denominado Alemoa. Segundo Gasparetto et al. (1988), essa formação, juntamente com as formações Caturrita e Botucatu, integra o Sistema Aquífero Guarani (SAG). Este sistema também é encontrado em alguns setores do topo e rebordo do Planalto Meridional Brasileiro, nos arenitos intertrápicos da formação Botucatu, entre os derrames de lava basáltica. (SILVÉRIO DA SILVA et al., 2004).

De acordo com Hausman (1995), na formação Santa Maria a circulação da água apresenta-se bastante regionalizada, sendo 
as vazões e rendimentos bastante irregulares. As deposições apresentam variações granulométricas locais, a circulação pode ser observada em horizontes escalonados, sem nenhuma interligação entre o membro superior e o inferior, fato demonstrado pela diferença química das duas águas.

\section{MATERIAIS E MÉTODOS}

A vulnerabilidade natural de aquíferos está diretamente relacionada com a infiltração, processo mais importante de recarga da água subterrânea no subsolo. O volume, a velocidade de infiltração e a proximidade do lençol freático dependem de vários fatores, que podem ser espacializados em planos de informação e integrados por geoprocessamento com o uso de pesos e notas.

Para obter uma base de dados que possibilite a integração, realizou-se uma busca de informações cartográficas já existentes da área em estudo, que, após selecionadas, foram digitalizadas no software ArcMap 9.2. Como não havia um levantamento cadastral dos poços com precisão topográfica $(x, y$ e $z)$, os mesmos foram georreferenciados e vinculados às informações obtidas nos testes de bombeamento realizados pela empresa Hidrobrasil Perfurações para a outorga dos mesmos junto à Secretaria Estadual do Meio Ambiente (SEMA - RS).

\section{ELABORAÇÃO DOS PLANOS DE INFORMAÇÃ̃O (PI)}

Para a elaboração do PI Nível Estático (NE) da água subterrânea, que é a distância em metros desde a boca do poço até o seu nível d'água em repouso, foram interpolados os valores dos 24 poços em funcionamento no campus da UFSM, utilizando-se para isso o aplicativo Surfer
8.0. Para a escolha do método de interpolação matemática, testaram-se os quatro métodos tidos como principais por Silva (2003): inverso do quadrado da distância, Krigagem, curvatura mínima e triangulação de Delaunay.

O georreferenciamento dos poços foi apoiado nos marcos da Rede de Referência Cadastral do campus da UFSM. Na área velha do campus, utilizou-se um taqueômetro eletrônico (estação total), marca Leika e modelo TC 407. Na área nova, como existem apenas dois marcos de referência, optou-se por realizar o georreferenciamento dos poços com receptor GPS de uma frequência (L1), marca Ashtech e modelo Promark 2, ambos equipamentos cedidos pelo Colégio Politécnico da UFSM.

As observações dos poços tubulares, situados na denominada área nova, predominantemente de uso rural, foram realizadas pelo método diferencial estático, com duração do rastreio de 30 minutos em cada poço. Para o pós-processamento dos dados levantados em campo com o receptor de GPS, foram copiados os arquivos digitais Rinex da estação SMAR (homologada pelo IBGE e situada sobre o Prédio 42 do Centro de Ciências Rurais da UFSM) e, em seguida, pós-processados no aplicativo Ashetch Solutions. Para a realização dos levantamentos em campo, contou-se com o auxílio de bolsistas do projeto SIG-UFSM e do projeto Plano Diretor dos campi da UFSM.

Os valores de Nível Estático (NE) e Nível Dinâmico (ND) dos poços foram obtidos por acompanhamento dos testes de bombeamento, realizados pela empresa Hidrobrasil Perfurações durante os meses de setembro e outubro de 2008. Para o valor referente ao Nível Dinâmico (ND), ou seja, quando o poço encontrava-se em bombeamento, foi utilizado o valor máximo obtido, dentro das 24 horas de realização dos testes pela empresa, conforme as 
normas de outorga. No Brasil, as Unidades da Federação são responsáveis pelo licenciamento dos poços, assim, no estado do Rio Grande do Sul, a outorga compete à SEMA-RS. Para os dois poços que abastecem o prédio do INPE, foram utilizados os dados levantados por Moreira (2005).

Para a elaboração do PI Geologia utilizou-se o Mapa Geológico da Folha de Camobi, na escala original de 1:50.000, elaborado por Gasparetto et al. (1988), e a Carta Geotécnica de Santa Maria, essa na escala de 1:25.000, elaborada por Maciel Filho (1990). Ambos os levantamentos foram realizados e publicados pelo Departamento de Geociências da UFSM.

Com base na Carta de Uso da Terra da Cidade Universitária, elaborada por restituição aerofotogramétrica por Aguirre (1991), na escala original 1:5.000, foram extraídas as curvas de nível de 5 em $5 \mathrm{~m}$, a rede hidrográfica e o limite da área em estudo. O levantamento, então em meio analógico, foi digitalizado no aplicativo Spring 4.3.2, em projeto coordenado por José Américo de Mello Filho no ano de 2005. Com o uso das curvas de nível, gerou-se o modelo numérico do terreno (MNT), elaborado a partir da construção de grade de pontos com latitude, longitude e altitude conhecidas.

A identificação do Uso e Cobertura da Terra no campus da UFSM, para a elaboração do PI Recarga Total, foi realizada através da classificação visual da imagem Quickbird capturada do aplicativo Google Earth Pro. Essa classificação serviu para identificar as porções com cobertura florestal e as áreas construídas, as quais possuem infiltração diferenciada.

\section{ATRIBUIÇÃO DE PESOS E NOTAS}

O PI Geologia contém as informações referentes ao meio aquífero aflorante da área em estudo e à estrutura das camadas. Pela composição e propriedade de cada formação geológica, assim como pela estratigrafia - ou seja, a forma como as mesmas estão dispostas -, definiu-se a facilidade de infiltração de possíveis contaminantes. Para atribuição das notas referentes a cada formação, levou-se em consideração, ao se definir a vulnerabilidade das águas subterrâneas, a composição das camadas adjacentes não aflorantes no campus e visualizadas nos perfis dos poços como exemplo da formação. Rosário do Sul (aquífero de baixa produção e aquitardo - MACIEL FILHO, 1990). Como esse PI congrega mais de uma variável do método DRASTIC, ${ }^{1}$ a ele foi atribuído o maior peso.

Para isso, utilizaram-se o relatório técnico da Carta Geotécnica de Santa Maria, elaborada por Maciel Filho (1990), e os perfis dos poços tubulares disponíveis na página do SIAGAS/CPRM e em Moreira (2005). Também serviram de base para a atribuição das notas as cargas das classes do fator Aquifer Media do método DRASTIC, o qual é definido a partir de unidades geológicas e hidrogeológicas associadas aos tipos de aquíferos (livres, semiconfinados e confinados). (Quadro 1).

\begin{tabular}{|c|c|c|c|}
\hline Peso & $\begin{array}{c}\text { Variável e } \\
\text { fundamentação }\end{array}$ & Classe & Nota \\
\hline \multirow{2}{*}{$30 \%$} & $\begin{array}{c}\text { Terraços fluviais } \\
\text { (aquífero livre) }\end{array}$ & 9 \\
\cline { 3 - 4 } & $\begin{array}{c}\text { Geologia } \\
\text { (ALLER et al., } \\
\text { FILHO, 1990) }\end{array}$ & $\begin{array}{c}\text { Depósitos fluviais de } \\
\text { várzea (aquífero livre) }\end{array}$ & 8 \\
\cline { 3 - 4 } & $\begin{array}{c}\text { Formação. Santa Maria/ } \\
\text { Passo das Tropas } \\
\text { (aqf. livre) }\end{array}$ & 8 \\
\cline { 3 - 4 } & $\begin{array}{c}\text { Formação. Santa Maria/ } \\
\text { Alemoa (aquiclude) }\end{array}$ & 2 \\
\hline
\end{tabular}

continua

\footnotetext{
${ }^{1}$ De acordo com Aller et al. (1987), DRASTIC significa: D - Depth to water (Profundidade das águas subterrâneas); $\mathrm{R}$ - Recharge (Recarga total); A - Aquifer media (Meio aquífero); S - Soil media (Solos); T - Topography (Topografia); I - Impact of the vadose zone (Impacto na zona vadosa); C - Hydraulic condutivity (Condutividade hidráulica).
} 
conclusão

\begin{tabular}{|c|c|c|c|}
\hline \multirow{8}{*}{$25 \%$} & \multirow{8}{*}{$\begin{array}{l}\text { Profundidade da } \\
\text { água subterrânea } \\
\text { (ALLER et al., } \\
1987 \text { ) }\end{array}$} & $0-1,5 \mathrm{~m}$ & 10 \\
\hline & & $1,5-4,6 m$ & 9 \\
\hline & & $4,6-9,1 \mathrm{~m}$ & 7 \\
\hline & & $9,1-13 m$ & 5 \\
\hline & & $13-18 m$ & 4 \\
\hline & & $18-23 m$ & 3 \\
\hline & & $23-31 m$ & 2 \\
\hline & & $>31 \mathrm{~m}$ & 1 \\
\hline \multirow{3}{*}{$20 \%$} & \multirow{3}{*}{$\begin{array}{c}\text { Recarga } \\
\text { (ALLER et al., } \\
\text { 1987; } \\
\text { H A U S M A N, } \\
1995 \text { ) }\end{array}$} & Cobertura florestal & 4 \\
\hline & & Demais áreas & 3 \\
\hline & & Setor construído & 1 \\
\hline \multirow{5}{*}{$15 \%$} & \multirow{5}{*}{$\begin{array}{c}\text { Declividade } \\
\text { (ALLER et al., } \\
\text { 1987) }\end{array}$} & $0-2 \%$ & 10 \\
\hline & & $2-6 \%$ & 9 \\
\hline & & $6-12 \%$ & 5 \\
\hline & & $12-18 \%$ & 3 \\
\hline & & $>18 \%$ & 1 \\
\hline \multirow{4}{*}{$10 \%$} & \multirow{4}{*}{$\begin{array}{l}\text { Geomorfologia } \\
\text { (PEREIRA et } \\
\text { al., 1989; ROSS, } \\
\text { 2003) }\end{array}$} & Banhado & 10 \\
\hline & & Topo de Coxilhas & 8 \\
\hline & & Planície aluvial & 5 \\
\hline & & Planícies & 1 \\
\hline
\end{tabular}

Quadro 1 - Notas e pesos usados na avaliação da vulnerabilidade natural das águas subterrâneas Org.: MARION, 2009

A profundidade das águas subterrâneas é a variável que mais tem interferência no risco de poluição, uma vez que, quanto mais próximo da superfície for o lençol freático, mais facilmente um possível contaminante o atingirá. É obtido pela mensuração do Nível Estático (NE), ou seja, quando o poço encontra-se em situação de repouso. Para a determinação das classes e suas respectivas notas, utilizou-se como base o modelo DRASTIC.

O fator recarga total (recarga pela infiltração da chuva), considerado pelo modelo DRASTIC, está relacionado com a quantidade de água que atinge a zona saturada, ou seja, condiciona o transporte dos poluentes que possivelmente poderão atingir o aquífero. De maneira geral, quanto maior for a recarga, maior será o acúmulo de água no subsolo. Porém, havendo atividades com potencial de poluição em superfície, poderá haver transporte de substâncias poluidoras até o aquífero. De acordo com Hausman (1995), a infiltração anual para a área estudada varia entre 50 e 100 mm/ ano e o modelo DRASTIC atribui nota 3 para o intervalo semelhante de recarga, entre 51,85 a $103,7 \mathrm{~mm} /$ ano.

Apesar de o modelo DRASTIC utilizar apenas a recarga generalizada, sem levar em consideração as diversas formas de uso e cobertura da terra, neste trabalho foi realizada a diferenciação da nota entre o setor urbanizado do campus e as áreas com cobertura florestal. Por isso, atribuiu-se nota 4 para as áreas com cobertura florestal e, para as áreas impermeabilizadas (setor construído), atribuiu-se a nota mínima 1, o que equivale, de acordo como modelo DRASTIC, ao intervalo entre 0 a $51,85 \mathrm{~mm} /$ ano (Figura 2).

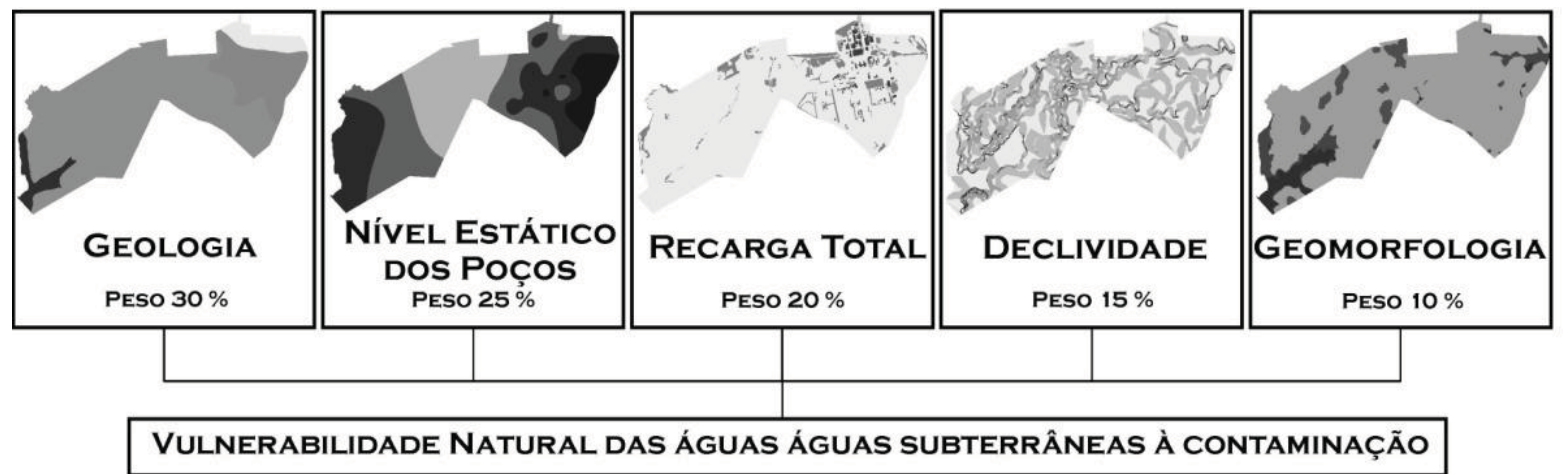

Figura 2 - Organograma dos mapas gerados na pesquisa e utilizados na avaliação ambiental, com seus respectivos pesos

Org.: MARION, 2009 
$\mathrm{O}$ fator declividade constitui um dos fatores do modelo DRASTIC e, embora não apareça em alguns métodos, como no GOD, é de fundamental importância para o levantamento da vulnerabilidade natural dos aquíferos. Quanto maior for a inclinação de um determinado terreno, maior será o escoamento superficial direto, diminuindo a infiltração. Superfícies suavemente onduladas permitem o escoamento superficial menos veloz, aumentando a possibilidade de infiltração. $\mathrm{O}$ intervalo das classes utilizadas neste trabalho, e suas respectivas notas para a declividade, são as mesmas do modelo DRASTIC.

O PI Geomorfologia foi construído com apoio metodológico em Ross (2003), segundo o qual a elaboração de cartas de Geomorfologia é dividida em seis níveis taxonômicos. Para este estudo empregouse o terceiro nível, que corresponde ao modelado, ou seja, formas que geneticamente foram ou estão sendo geradas por processos denudacionais ou agradacionais.

A Geomorfologia é uma variável ainda pouco explorada nos estudos de vulnerabilidade de aquíferos. Entretanto, a forma do relevo tem grande influência no fluxo e na recarga da água subterrânea. Assim, faz-se necessária a abordagem do relevo nos estudos de vulnerabilidade, uma vez que, conforme Rebouças (2002), por regra geral as zonas de recarga das águas subterrâneas, que são captadas por um poço profundo, são as colinas distantes. Barreto (2006) também constatou, por balanço hídrico em bacia representativa, que terrenos mais planos e cotas topográficas mais elevadas tendem a produzir uma maior recarga direta do aquífero.

Os processos denudacionais elaboram as formas esculturais do relevo através da dissecação por ação física e bioquímica, tendo como energia o clima pretérito e atual e sendo as principais áreas de recarga aquífera. Já os processos agradacionais elaboram formas de relevo por deposição (acumulação de sedimentos, quer seja em ambientes fluviais, lacustres marinhos ou eólicos) e são áreas, em muitos casos, sujeitas a inundações.

Assim, considerou-se para o campus da UFSM os topos das coxilhas como áreas de denudação, que sofrem o processo de dissecação (perda de material) com maior intensidade, como áreas mais vulneráveis, uma vez que é geralmente no topo dessas coxilhas que ocorre a recarga das águas subterrâneas. As "coxilhas pampeanas", assim denominadas segundo o Mapa Geomorfológico do IBGE/INCRA (1972 apud PEREIRA et al, 1989), são colinas côncavoconvexas, suaves e contínuas, associadas à extensa planície da Depressão Central.

As planícies aluviais, como foram classificadas por Pereira et al. (1989), são áreas de agradação (acúmulo de material) que podem ser áreas de inundação e, por serem áreas deprimidas, o nível freático é geralmente mais próximo. Por esse motivo, são consideradas zonas de média vulnerabilidade. Já as áreas de banhado são locais onde possivelmente ocorre a descarga de algum lençol, acarretando restrições à ocupação.

As notas atribuídas às classes dos mapas, na avaliação do aplicativo SAGA, variaram de 0 a 100, por isso, multiplicou-se por 10 as notas do Quadro 1. Nesse caso, por tratar-se de uma avaliação direta, quanto maior a nota, maior o risco que aquela classe apresenta à percolação de possíveis contaminantes e infiltração ao aquífero. No mapa final, as notas foram agrupadas nas classes de vulnerabilidade definidas por Foster et al. (2003): desprezível, baixa, média, alta e extrema. Em seguida, as notas e classes foram quantificadas e analisadas, utilizando-se o módulo Assinatura do SAGA 2007 e o relatório final gerado pela avaliação. O acabamento dos mapas foi realizado nos aplicativos computacionais CorelDraw X3 e Corel Photo-Paint X3. 


\section{RESULTADOS}

O Mapa Geológico recebeu maior importância no estudo (30\%), conforme mostra a Figura 2, por a ele serem atribuídos dois fatores na avaliação: as propriedades da formação geológica ocorrente e a disposição das camadas adjacentes. Para isso, definiram-se as unidades geológicas e hidrogeológicas associadas aos tipos de aquíferos (confinados, semiconfinados e livres). O parâmetro refere-se à capacidade de atenuação e transmissividade da rocha, que ocorre em função dos minerais constituintes, grau de cimentação, da granulometria e porosidade. Uma rocha, formada por minerais grosseiros ou com fraturas, por exemplo, possui menor capacidade de atenuar possíveis poluentes.

A profundidade da água subterrânea é o fator mais importante para a avaliação da vulnerabilidade. Trata-se do Nível Estático dos poços, ou seja, a distância entre o nível de água em repouso e a "boca do poço". A mensuração desse Nível Estático foi realizada com medidor especial conhecido como freatímetro sonoro, sendo que a variação encontrada foi entre 15,35 a $40 \mathrm{~m}$ de distância. O valor zero corresponde aos poços jorrantes - ou às fontes que afloram em superfície -, situação essa não encontrada nos poços do campus da UFSM. Isso diminui o risco de contaminação da água subterrânea, uma vez que a maior proximidade encontrada do lençol freático foi de $15,35 \mathrm{~m}$ no poço PB12, localizado no Parque de Exposições da UFSM.

$\mathrm{Na}$ área em estudo, tem-se uma precipitação média anual entre 1.600 a 1.800 mm/ ano sem estação seca ou chuvosa definida. Desses, estima-se com base em Hausman (1995) que aproximadamente 50 a 100 $\mathrm{mm}$ /ano se infiltrem para recarga do Sistema Aquífero Guarani (o que corresponde a nota 3, segundo o modelo DRASTIC). Embora o modelo DRASTIC possua o fator
Recharge (recarga), o mesmo não considera o uso e a cobertura da terra na infiltração. Optou-se aqui por distinguir três classes de uso, com diferença na infiltração (em ordem crescente de infiltrabilidade): cobertura florestal, demais áreas (campo, lavoura experimental e gramado) e área construída.

A declividade no campus da UFSM é pouco acentuada: como na maioria das áreas da Depressão Central, apresenta-se de forma suave, o que favorece a infiltração e diminui o escoamento superficial. Entre as classes estudadas, predominam aquelas com declividade inferior a $2 \%(42,4 \%$ da área em estudo), seguidas das seguintes classes: $2 \%$ a $6 \%$ (31,7\% de abrangência), $6 \%$ a $12 \%(21,8 \%), 12 \%$ a $18 \%(3,1 \%)$ e, na classe com inclinação superior a $18 \%$, apenas $0,9 \%$ da área total. A predominância de baixa declividade contribui para o aumento da vulnerabilidade das águas subterrâneas, devido ao fato de essa variável favorecer a infiltração.

As notas resultantes da avaliação oscilaram entre 17 a 66 (Tabela 2). As classes de vulnerabilidade foram baseadas em Foster et al. (2003), que vão de 0 a 1. Para adaptar as notas da avaliação àquelas geradas pelo SAGA, multiplicou-se essa escala por 100. Assim, as notas obtidas entre 17 (nota mais baixa) a 30 foram definidas como de vulnerabilidade baixa. A partir de 31 até 49, definiu-se como de média vulnerabilidade. Já as notas acima de 50, até a maior encontrada (66), foram definidas como de vulnerabilidade alta. De acordo com essa escala, baseada em Foster et al. (2003), as notas acima de 70 seriam classificadas como de vulnerabilidade extrema; entretanto, não foram encontradas. 
Tabela 2 - Hierarquia das classes de vulnerabilidade natural determinadas no zoneamento Org.: MARION, 2009

\begin{tabular}{c|c|c}
\hline $\begin{array}{c}\text { Classe de } \\
\text { vulnerabilidade natural }\end{array}$ & $\begin{array}{c}\text { Notas obtidas na } \\
\text { avaliação }(0-100)\end{array}$ & Porcentagem \\
\hline Baixa & $17-30$ & $32,12 \%$ \\
\hline Média & $31-49$ & $47,17 \%$ \\
\hline Alta & $50-66$ & $20,71 \%$ \\
\hline
\end{tabular}

Nota: Não foram encontradas notas abaixo de 17 e acima de 66

No campus da UFSM predomina a vulnerabilidade média, com 47,17\% de abrangência sobre a área, o que corresponde a quase metade da área total do campus. Já a vulnerabilidade alta possui $20,71 \%$ de abrangência, que ocorre em duas áreas do estudo: no leste e a sudoeste. $\mathrm{Na}$ área de vulnerabilidade alta, situada a leste do campus e representada pela cor vermelha, é desenvolvida a maioria das atividades, por ser a região urbanizada do campus e onde foi perfurada também a grande maioria dos poços tubulares para abastecer a demanda local.

A vulnerabilidade baixa abrange 32,12\% e foi identificada em alguns setores da área velha, onde se situa o Jardim Botânico e, em sua grande maioria, na área nova. Em termos de conservação das águas subterrâneas, os locais com baixa vulnerabilidade são os mais adequados para a expansão do campus, uma vez que a quantidade de nitrato, gerado pelos dejetos do homem, também é potencialmente poluidor. A área identificada como de baixa vulnerabilidade possibilita a expansão do campus, sem a necessidade de remoção da cobertura florestal. Utilizando técnicas de geoprocessamento, como a combinação dos mapas, e mediante a quantificação das combinações no módulo Assinatura do SAGA 2007, verificou-se que apenas 17,415 hectares possuem cobertura florestal, considerando o total de 366,798 hectares da classe vulnerabilidade baixa, o que equivale a menos de $5 \%$.
O método utilizado mostrou resultados satisfatórios e recomenda-se que o mesmo seja testado em diferentes áreas para comparar sua eficácia. Após a aplicação da avaliação ambiental por geoprocessamento, de forma zonal, para a identificação da vulnerabilidade natural dos aquíferos no ambiente matricial do SAGA 2007, é possível realizar uma comparação com a avaliação pontual, espacializada por interpolação e encontrada na grande maioria dos trabalhos da literatura, como por exemplo em Marion, Mello Filho e Silvério da Silva (2008).

A avaliação pontual possibilita a atribuição de nota pontual pela média das notas das camadas (estratos) ao longo de todo o perfil do poço. É necessário, entretanto, um número satisfatório de perfis de poços e que esses estejam bem distribuídos sobre a área em estudo. O método de interpolação utilizado para espacializar os dados pontuais interfere significativamente nos resultados, assim, quando não tiverem sido tomados os dados do perfil para algum poço, os valores deverão ser obtidos por interpolação, a partir das características dos poços mais próximos.

A avaliação zonal por geoprocessamento possibilita a avaliação das ocorrências na totalidade da área por classes e pelo peso dos planos de informação, além da integração com demais mapas. É necessário, todavia, um mapeamento preliminar adequado com a escala de trabalho. As camadas adjacentes são consideradas como se ocorressem em toda a extensão abaixo da camada livre.

O produto final da avaliação zonal por geoprocessamento foi o Mapa da vulnerabilidade natural à contaminação das águas subterrâneas, exposto na Figura 3. Esse deve compor um dos pilares do planejamento territorial e, em especial, dos Planos Diretores. O mapa mostra como os responsáveis pelo ordenamento das atividades nos municípios deveriam realizar o planejamento adequado de uso e ocupação do solo. 


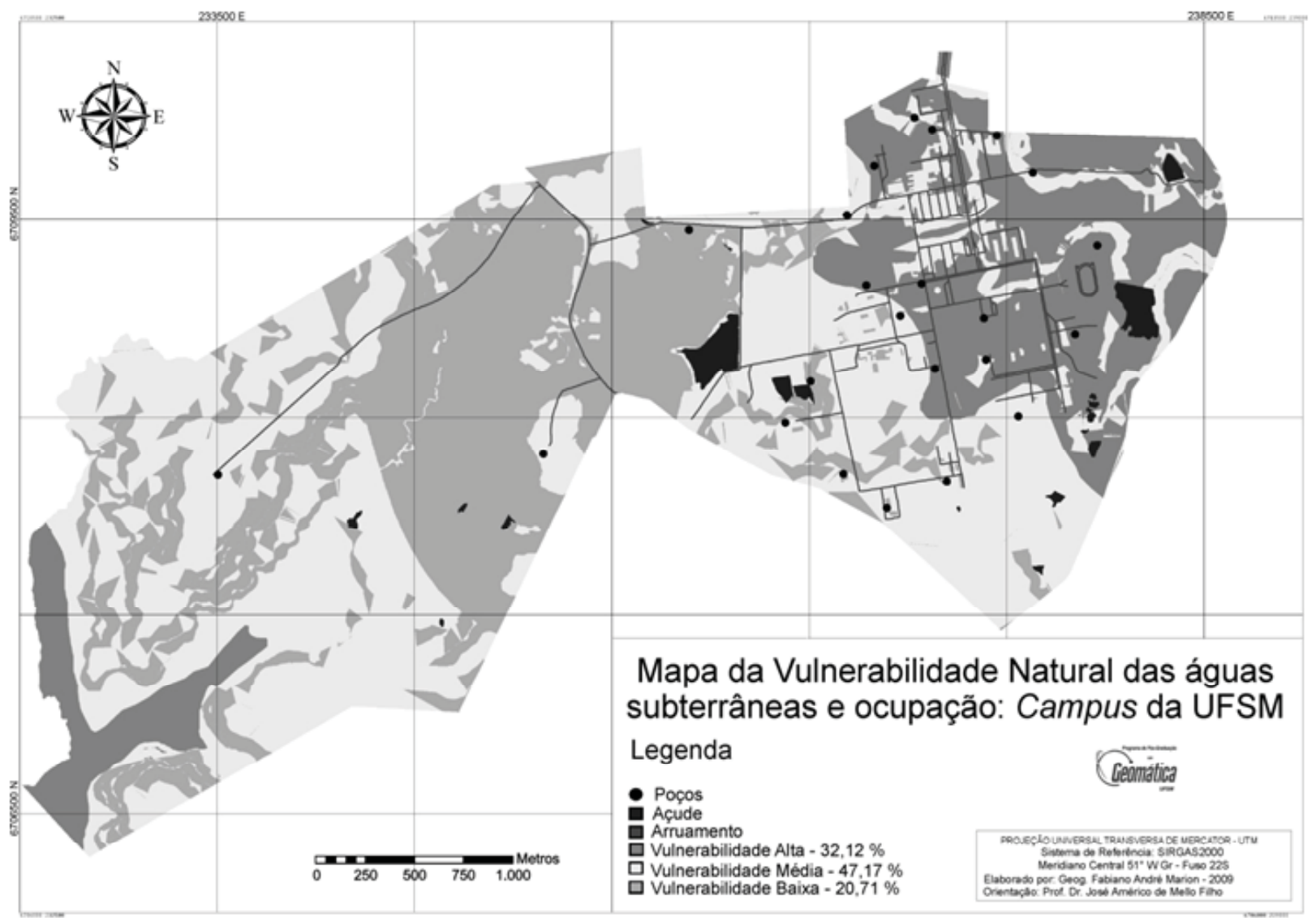

Figura 3 - Mapa da vulnerabilidade natural à contaminação das águas subterrâneas no campus da UFSM

Esse mapa é fundamental por definir a locação de distritos industriais, depósitos, aterros sanitários, cemitérios, postos de combustíveis, ou qualquer outra atividade com potencial poluidor e que possa oferecer risco de contaminação às águas subterrâneas.

Dessa forma, um Plano Diretor, para ser eficiente, legal e ambientalmente responsável, deve recomendar, juntamente com outros estudos, a instalação de atividades potencialmente contaminantes em locais de baixa vulnerabilidade e, preferencialmente, à jusante do fluxo subterrâneo dos poços de captação utilizados para o abastecimento humano. Deve, também, restringir a locação das atividades potencialmente contaminantes nas áreas de vulnerabilidade alta e extrema, uma vez que, caso seja efetuada, oferecerá risco eminente de contaminação.

\section{CONSIDERAÇÕES FINAIS}

Atualmente a poluição dos recursos hídricos subterrâneos vem se mostrando uma preocupação cada vez maior, tanto para a população quanto para os órgãos gestores. Entretanto, a sua contaminação e exploração continuam ocorrendo em demasia. Estudos como este ajudam a alertar a população e os órgãos competentes quanto à necessidade da conservação dos aquíferos.

Dessa forma, sempre é valido lembrar que, uma vez contaminados, a descontaminação dos aquíferos torna-se difícil e onerosa. Ademais, mesmo não apresentando vulnerabilidade significativa, um aquífero, quando exposto a sucessivas cargas contaminantes, pode ter sua vulnerabilidade à contaminação agravada.

Diante disso, num segundo trabalho será apresentada a avaliação do risco de 
contaminação das águas subterrâneas com o uso do geoprocessamento, através da verificação em campo das atividades potencialmente contaminantes. As possíveis áreas de influência dessas atividades foram interagidas com o mapa das áreas vulneráveis a contaminação, verificando, assim, se e onde ocorrem os riscos eminentes de contaminação das águas subterrâneas.

\section{REFERÊNCIAS}

AGUIRRE, J. A. Carta de uso da terra da cidade universitária - UFSM Escala 1:5.000. Santa Maria: CCR-Departamento de Engenharia Rural, 1991.

ALLER, L., et al. DRASTIC: a standardized system for evaluating groundwater pollution potencial using hydrogeologic setting. United States: EPA, 1987.

BARRETO, C. E. A. G. Balanço hídrico em zona de afloramento do Sistema Aquífero Guarani a partir de monitoramento hidrogeológico em bacia representativa. Dissertação Mestrado em Engenharia Civil - Hidráulica e Saneamento. Escola de Engenharia de São Carlos, Universidade de São Paulo. São Carlos, 2006.

BRASIL. Ministério da Saúde. Portaria n. 518, 25 mar. 2004. Atualiza as disposições da Portaria ${ }^{\circ}$ 1469, 29 dez. 2000. Brasília, 2004. Disponível em: <http:// portal.saude.gov.br/portal/arquivos/ pdf/portaria_518_2004.pdf> Acesso em: 29 nov. 2008.

DA-ROSA, A. A. S. Sítios fossilíferos de Santa Maria, RS, Brasil. Revista Ciência \& Natura, v. 26, n. 2. Santa Maria: UFSM, dez. 2004.

FOSTER, S. et al. Protección de la calidad del agua subterránea: guia para empresas de agua, autoridades municipales y agencias ambientales, 2 . ed. Madri: Ediciones Mundi - Prensa, 2003.

GASPARETTO, N. V. L. et al. Mapa geológico da folha de Santa Maria: texto explicativo. FINEP UFSM, 1988.

GOVERNO DO ESTADO DO RIO GRANDE DO SUL. SECRETARIA DO MEIO AMBIENTE. Código Estadual do Meio Ambiente. Lei Estadual $\mathbf{n}^{\circ}$ 11.520 de 03.08.2000. Porto Alegre, SEMA/SEMA/ FZB, 2000.

GREGORASHUK, J. de los S. Estúdio del uso actual y potencial del acuífero Guaraní: jan. 2001. Disponivel em: <http:/ www.sg-guarani.org.pdf>. Acesso em: 02 mar. 2007.
HAUSMAN, A. Províncias hidrogeológicas do Estado do Rio Grande do Sul - RS. Acta Geologica Leopoldensia: Série Mapas, escala 1:50.000. n. 2, p. 1-127, 1995.

MACIEL FILHO, C. L. Carta geotécnica de Santa Maria. Santa Maria: UFSM, imprensa universitária, 1990.

MARION, F. A.; MELLO FILHO, J. A; SILVÉRIO DA SILVA, J. L. Situação atual dos recursos hídricos subterrâneos em Itaara - RS e sua vulnerabilidade natural. Revista Geografia Ensino \& Pesquisa. Santa Maria, v. 12, n. 1, mai. 2008.

MOREIRA, C. M. D. Aspectos qualitativos da água subterrânea no campus da UFSM, Santa Maria RS. 174f. Dissertação (Mestrado em Engenharia Civil) - Universidade Federal de Santa Maria, Santa Maria, 2005.

NIMER, E. Clima. In: FURLANETTO, D. A. et. al. Geografia do Brasil: região sul. Rio de Janeiro: IBGE, v. 2, 1990.

PEREIRA, L. et al. Contribuição à Geografia Física do município de Santa Maria: geomorfologia. Revista Geografia Ensino \& Pesquisa. Santa Maria: n. 3, dez p. 37-68, 1989.

REBOUÇAS, A. da, C. Águas Subterrâneas. In: BRAGA, B.; REBOUÇAS; A. da, C; TUNDISI, J. G. (Org.). Águas doces no Brasil: capital ecológico, uso e conservação. São Paulo: Escrituras Editora, 2. ed., p. 119-149, 2002.

ROSS, J. L. S. Geomorfologia: ambiente e planejamento. São Paulo: Contexto, 7. ed., 2003. 85 p.

SILVA. A. de B. Sistemas de informações georeferenciadas: conceitos e fundamentos. Campinas: UNICAMP, 2003. 236 p.

SILVERIO DA SILVA, J. L. et al. Caracterização de áreas de recarga e descarga do sistema aquífero Guarani em Santana/Rivera e Quaraí/Artigas e estudo da vulnerabilidade natural em Quaraí/Artigas. Santa Maria: UFSM-UDeLaR, 2005. 200 p.

XAVIER DA SILVA, J. Geoprocessamento para análise ambiental. Rio de Janeiro: Ed. do autor, 2001. 227 p.

ZOBY, J. L. G.; OLIVEIRA, F. R. Panorama da qualidade das águas subterrâneas no Brasil. Brasília: Agência Nacional de Águas - ANA, 2005. Disponível em: <http://www.ana.gov.br/pnrh_novo/ documentos/panorama.pdf $>$. Acesso em: 16 ago. 2008.

Recebido em 06/05/10

Aceito para publicação em 01/07/10 